\title{
A Review on Impact of Climate Change on Food Production
}

\author{
Shashi Kiran C R \\ Research Scholar, Civil Engineering, \\ BMS College of Engineering, Karnataka, India \\ Dr. M C Sampathkumar \\ Professor, Civil Engineering, \\ BMS College of Engineering, Karnataka, India
}

\begin{abstract}
Climate change affects the livelihoods of poor and rich alike by impacting basic human needs including food, clothing and shelter requirements. Assessments of Impacts and Adaptations to Climate Change enhances capabilities in the developing world for responding to climate change by building scientific and technical capacity, advancing scientific knowledge, and linking scientific and policy communities. Agriculture and food security are key sectors for intervention which are highly vulnerable to climate change. The present article is an attempt to study the influence of climate change such as rainfall, temperature, humidity etc. on food production.
\end{abstract}

Keywords - Climate change, Food Security, Agriculture, Food Production.

\section{INTRODUCTION}

Human beings have learned to live with climate variability on various timescales, from daily to decadal. However, the climate variability we are accustomed to is changing quickly, accompanied by change in seasonal variations, pattern of rainfall, depleting soil fertility, a rise in global mean temperature due to increasing greenhouse-gas concentrations in the atmosphere. The poor in developing countries who already have difficulties in coping with current climate variability will be even more vulnerable. They are the ones who contribute the least to the climate change, yet need to learn to cope with changing climate with few financial or technical resources.

Climate change affects livelihoods of poor and rich alike by impacting basic human needs, including food, clothing and shelter requirements. The four components of food security, food availability, food access, food utilization and food production system stability. Inefficiencies in food supply chains have a negative impact on the environment, lower productivity and waste food. Current farming practices, including land clearing and inefficient use of fertilizers and organic residues. From the farm gate to consumers, refrigeration and other supply chain activities are an additional major source of greenhouse gas emissions. As global demand for food, fodder and bio-energy crops grows, many agricultural systems are depleting soil fertility, biodiversity and water resources. In many regions there are large gaps between potential and actual crop yields.

In India, agriculture mainly depends on monsoon (rainfall), Climate change is likely to worsen the situation in parts of the world that already experience high levels of food insecurity. Greater variability of rainfall has significant repercussions for food security, the livelihoods of millions of people, and the migration decisions of vulnerable households. In order to make informed decisions about adaptation planning, development, and a transition to a more climate resilient future, policymakers and development actors need a better understanding of the linkages among changes in the climate, household livelihood and food security profiles, and migration decisions.

\section{OBJECTIVE OF THE STUDY}

The objective of the present study is to evaluate the effects of climate change and its impact on food security. 


\section{III.REVIEW OF LITERATURE}

\section{P. S. Brahmanand et. al. (2013) [1]}

Conducted a study on need for achieving food security is felt significantly in the recent years due to enormous pressure from the ever-increasing population in India. Owing to the change in preferences in crop production techniques over a period of time, several new challenges draw attention to food security. The article discusses various challenges to food security in India. Critical analysis is made on challenges like crop diversification, issues related to bio-fuel and medicinal plant cultivation, climate change, mismatch between water demand and availability, recent status in production of high yielding crop varieties and agricultural crop pricing and insurance and new trends in globalization and urban encroachments

The article concluded that food security in India can be achieved by paying higher attention to issues such as climate change, integrated water management, agricultural pricing and crop insurance. The impact of globalization in the form of SEZs and other factors has been both positive and negative in terms of agricultural prosperity and there is a strong need to regulate the policies related to globalization for reducing its negative effects on food security in India

\section{Josef Schmidhuber et. al. (2007) [2]}

Conducted a study on the potential impacts of climate change on food security. It was found that of the four main elements of food security, i.e., availability, stability, utilization, and access, only the first is routinely addressed in simulation studies. To this end, results indicate that the impacts of climate change are significant, however, with a wide projected range (between 5 million and 170 million additional people at risk of hunger by 2080) strongly depending on assumed socio-economic development. The likely impacts of climate change on the other important dimensions of food security are discussed qualitatively, indicating the potential for further negative impacts beyond those currently assessed with models. Finally, strengths and weaknesses of current assessment studies were discussed, suggesting improvements and proposing avenues for new analyses.

The article concludes that climate change will affect all four dimensions of food security, namely food availability (i.e., production and trade), access to food, stability of food supplies, and food utilization. The importance of the various dimensions and the overall impact of climate change on food security will differ across regions and over time and, most importantly, will depend on the overall socio-economic status that a country has accomplished as the effects of climate change set in. Essentially all quantitative assessments show that climate change will adversely affect food security. Climate change will increase the dependency of developing countries on imports and accentuate existing focus of food insecurity to a lesser extent. Within the developing world, the adverse impacts of climate change will fall disproportionately on the poor. Many quantitative assessments also show that the socio-economic environment in which climate change is likely to evolve is more important than the impacts that can be expected from the biophysical changes of climate change. Less is known about the role of climate change for food stability and utilization, at least in quantitative terms. However, it is likely that differences in socio-economic development paths will also be the crucial determinant for food utilization in the long run and that they will be decisive for the ability to cope with problems of food instability, be they climate-related or caused by other factors.

Finally, all quantitative assessments we reviewed show that the first decades of the 21 st century are expected to see low impacts of climate change, but also lower overall incomes and still a higher dependence on agriculture. During these first decades, the biophysical changes as such will be less pronounced but climate change will affect those particularly adversely that are still more dependent on agriculture and have lower overall incomes to cope with the impacts of climate change. By contrast, the second half of the century is expected to bring more severe biophysical impacts but also a greater ability to cope with them. The underlying assumption is that the general transition in the 
income formation away from agriculture toward non agriculture will be successful. How strong the impacts of climate change will be felt over all decades will crucially depend on the future policy environment for the poor. Freer trade can help to improve access to international supplies; investments in transportation and communication infrastructure will help provide secure and timely local deliveries; irrigation, a promotion of sustainable agricultural practices, and continued technological progress can play a crucial role in providing steady local and international supplies under climate change.

III Mohammad Karamouz et. al. (2013) [3]

Increasing water scarcity and competition for water resources from different sectors drive the need to improve crop productivity to ensure adequate food for current and future development stages relying on uncertain water availability for agriculture. This can be achieved because available information indicates that there is a wide gap between actual and attainable crop water productivity. Quantifying crop water productivity reveals gaps in knowledge regarding the best ways to utilize water. Most of these gaps relate to inability to quantify all flow components in the considered region, their interactions with the plants and crops, agricultural productivity, and the environmental demand in the process of producing marketable yields. It is hypothesized that advances in modeling, information and communication technologies will accelerate understanding the previous interrelated factors and the identification of interventions.

In this study, an agricultural planning optimization-simulation model is developed to determine the optimal cultivated area, cropping pattern and irrigation efficiency considering limited water supply resources in a region. To study the potential regional-scale impacts of climate change on the crop water requirements and water supply, future climate change scenarios obtained from the GCM outputs are considered. It was suggested to do further research in order to evaluate other climate change scenarios as a part of this work extension. In order to downscale the climate regional data, the LARS-WG model is used. Then, for simulating the watershed stream flow, the IHACRES model is run using the LARS-WG outputs. The CROPWAT model is used with downscaled climate data and the reference evapotranspiration is calculated for each climate scenario by utilizing the FAO Penman-Montieth method. As a case study, the Aharchay watershed located in the northwestern part of Iran was simulated utilizing the WEAP model. This model is run based on different management scenarios to have a projection of future demands and water allocation. Simulated evapotranspiration time series under climate change scenarios show that ETo increases approximately 4, 10, and $12.1 \%$ in the periods of 2011-2030, 2046-2065, and 2080-2099, respectively. Consequently, agricultural water demand is increasing during different time periods. Also, simulated yearly stream flow under climate change impacts in all scenarios is decreasing. Taking into account these changes, the importance of considering climate effect in water resource and agricultural planning and management has been evaluated. Variations of crop pattern and improved irrigation efficiency in the study area under different management scenarios show that although scenario provides the best values of objective function because of having no constraint, the net benefit of an alternative scenario is preferable, emphasizing on cultivating orchards. This scenario is also consistent (almost the same cultivation area and crop pattern in different years), making it easier to implement. It is also based on the available water resources in dry conditions. In the study, the Tennant method is used for the evaluation of the environmental water demand of the Aharchay River. However, it is suggested to do further investigation before model implementation in the study area to determine environmental demand using other methods such as BBM. The results of the study show the significant value of using different tools in allocating scarce water resources in semiarid regions.

IV Dean F, Peterson et. al. (1990) [4]

Conducted a study on Warming of the global atmosphere by $2^{\circ}-5^{\circ} \mathrm{C}$, and regional changes in precipitation by mid 21 st century as greenhouse gases double, is expected. A composite model predicts the consequences on the geography of U.S. irrigation. Percentages of cultivated area irrigated are projected for each state. Predictions of 
actual area irrigated, which will depend on economic conditions and availability of new water supplies are not made. In all cases percentages irrigated rise, with the greatest impact of a warmer climate on the agricultural economy in the Western states. In the Western states this will occur because of decreases in total area cultivated due to a loss of rainfall agriculture. In the East, irrigation will increase, accompanied by some decrease in cultivated areas. Improved use of technologies could help meet increasing evapotranspiration needs, but large new surface supplies will generally be required to maintain or increase present levels of irrigation.

The article concludes that given the impossibility of projecting irrigated areas under changed climatic conditions, the projected future percent of cultivated area irrigated by states is proposed as the geographical indicator of climate change effects on irrigation.

Although the writers used a fixed scenario, conclusions are quite sensitive to choice of scenario, especially with regard to precipitation. Changes in precipitation rapidly offset temperature effects. This sensitivity to precipitation is somewhat obscured in the West under the writers' scenarios because it is tied to present values. A wide range of contrasting conclusions is possible within the range of projected regional precipitation. For the present, the writers' midstream scenarios probably provide the best general picture of the main issues.

The greatest impact of a $3^{\circ} \mathrm{C}$ warmer climate on the agricultural economy will be in the West, where irrigators will be hard put to maintain even present levels of irrigation. The largest effects will occur in the high plains with minor effects in the Pacific Northwest. Although the writers' modest scenarios show relatively mild consequences in the East, the resilience of agro climatic ecologies is substantially reduced for the $+3^{\circ} \mathrm{C}$, and $+3^{\circ} \mathrm{C}$ and $10 \%$ decrease in precipitation cases, and rather modest increases in severity would trigger dramatic changes in the future of rain fed agriculture east of the 100th meridian. At least part of increased NIR could be met by improved irrigation technology, some new water supplies will be needed and some will be costly. Although river withdrawals are less than $1 / 3$ and consumption is less than $1 / 15$, water is not readily available when and where needed, and present uses press ground-water even harder. Few states are without severe shortages according to the 1983 National water summary ("National Water" 1984). Maintenance or expansion of present irrigated areas will require development of large-scale surface storage and conveyance.

\section{Parisa-Sadat Ashofteh et. al. (2014) [5]}

Conducted a study on assesses the risk of increase in water demand for a wide range of irrigated crops in an irrigation network located downstream of the Aidoghmoush Dam in East Azerbaijan by considering climate change conditions for the period 2026-2039. Atmosphereocean global circulation models (AOGCMs) are used to simulate climatic variables such as temperature and precipitation. The Bayesian approach is used to consider uncertainties of AOGCMs. Climate change scenarios of climatic variables are first weighted by using the mean observed temperature-precipitation (MOTP) method, and related probability distribution functions are produced. Outputs of AOGCMs are used as input to water requirement models. Then, produced by using the Monte Carlo method, 200 samples (discrete values) from the probability distribution functions of monthly downscaled temperature and precipitation in the study area are extracted by using software for sensitivity and uncertainty analysis. Time series of climatic variables in future periods are then generated (temperature variable to calculate potential evapotranspiration and rainfall variable to calculate effective rainfall). To estimate crop water requirements, crop evapotranspiration (from the product of potential evapotranspiration in the previous step and coefficient of crop computed) and effective precipitation (from time series of the previous step) are calculated. The Food and Agricultural Organization of the United Nations (FAO) methods, FAO-24 and Penman-Monteith, were used to compute crop and potential evapotranspiration, respectively. Because of lack of required data, potential evapotranspiration in future periods is computed through the relationship of temperature and potential evapotranspiration in the baseline period; the same procedure is conducted for temperature. Net water requirement (NWR) and the risk of changes in water demand volume of crops (e.g., wheat, barley, alfalfa, soybean, feed corn, forage, potato, and walnut orchards) are computed 
by entering 200 monthly time series of downscaled temperature and precipitation in future periods. The results indicate that risk of changes in crop water requirements increases by approximately $3 \%$ for a $25 \%$ risk, approximately $17 \%$ for a $50 \%$ risk, and approximately $33 \%$ for a $75 \%$ risk. Also, based on the current cultivated area, on average, the volume of water demand only for the fore mentioned crops will be approximately 2.5(106 $\mathrm{m} 3 /$ year) with a risk of $25 \%$, approximately $16(106 \mathrm{~m} 3 /$ year) with a risk of $50 \%$, and approximately $31(106$ $\mathrm{m} 3=$ year) with a risk of $75 \%$. Wheat and barley are more resistant and less sensitive to climate change than other crops considered.

The article investigated the risk of agricultural crops' water demand under climate change by using AOGCMs. The evaluation of monthly temperature under climate change scenarios in future periods showed that average temperature changes will increase from 0.56 to $0.83^{\circ} \mathrm{C}, 0.83$ to $2.54^{\circ} \mathrm{C}, 0.75$ to $1.90^{\circ} \mathrm{C}$, and 0.24 to $1.61{ }^{\circ} \mathrm{C}$ in the spring to winter seasons, respectively, whereas for average precipitation, seasonal changes will increase from 0.69 to $1.17 \mathrm{~mm}, 0.45$ to $1.41 \mathrm{~mm}, 0.9$ to $2.16 \mathrm{~mm}$, and 0.89 to $1.28 \mathrm{~mm}$.

The results of weighting AOGCMs showed that for temperature and precipitation, a dominant pattern was not observed among the models. Generally, the GFDL R30 and HadCM3 models had higher weight relative to other models for simulating climatic variables. The results showed that crops' water requirement will increase with the increase of risk in the future period, such that this increase will be approximately $3 \%$ for a risk of $25 \%$, approximately $17 \%$ for a risk of $50 \%$, and approximately $33 \%$ for a risk of $75 \%$. On average, on the basis of the current area under cultivation of the irrigation network, water demand volume for the crops (wheat, barley, alfalfa, soybean, feed corn, forage, potato, and walnut orchards) will increase to approximately $2.5(\times 106 \mathrm{~m} 3 /$ year $)$ for a risk of $25 \%$, approximately $16(\times 106 \mathrm{~m} 3 /$ year $)$ for a risk of $50 \%$, and approximately $31(\times 106 \mathrm{~m} 3 /$ year) for a risk of $75 \%$. Conversely, the Aidoghmoush River discharge has a high risk to be reduced because of projected increases in water demand volumes. An increase in irrigation demand and a decrease in streamflow can be expected to occur in the study area.

The results also showed that in the study area, wheat and, particularly, barley can be more resistant to climate change. Therefore, a change in cropping pattern can be one of the adaptation strategies to climate change in this region. The study presented a methodology to investigate the risk of agricultural crops' water demand under climate change. The presented methodology could be performed on other regions with different historical climate and different crops. It could be useful for adaptation with climate change or mitigation of its impacts (e.g., with a changing cropping pattern, relative to the other management operations) especially for arid regions with water resource limitations.

The methodology used is easy because it requires less data, such as climatic variables (e.g., temperature and rainfall for the baseline and future periods), mean relative humidity, and monthly wind speed for the baseline period, and knowledge of crop (e.g., length of crop growth or cropping pattern).

VI M.L. Parry et. al. (2004) [6]

Conducted a study on analyses the global consequences to crop yields, production, and risk of hunger of linked socio-economic and climate scenarios. Potential impacts of climate change are estimated for climate change scenarios developed from the HadCM3 global climate model under the Intergovernmental Panel on Climate Change Special Report on Emissions Scenarios (SRES) A1FI, A2, B1, and B2. Projected changes in yield are calculated using transfer functions derived from crop model simulations with observed climate data and projected climate change scenarios. The basic linked system (BLS) is used to evaluate consequent changes in global cereal production, cereal prices and the number of people at risk from hunger. The crop yield results elucidate the complex regional patterns of projected climate variables, $\mathrm{CO} 2$ effects, and agricultural systems that contribute to aggregations of global crop production. The A1FI scenario, as expected with its large increase in global temperatures, exhibits the greatest decreases both regionally and globally in yields, especially by the 2080s. The contrast between the yield 
change in developed and developing countries is largest under the A2a-c scenarios. Under the B1 and B2 scenarios, developed and developing countries exhibit less contrast in crop yield changes, with the B2 future crop yield changes being slightly more favorable than those of the B1 scenario. When crop yield results are introduced to the BLS world food trade system model, the combined model and scenario experiments demonstrate that the world, for the most part, appears to be able to continue to feed itself under the SRES scenarios during the rest of this century. However, this outcome is achieved through production in the developed countries (which mostly benefit from climate change) compensating for declines projected, for the most part, for developing nations. While global production appears stable, regional differences in crop production are likely to grow stronger through time, leading to a significant polarization of effects, with substantial increases in prices and risk of hunger amongst the poorer nations, especially under scenarios of greater inequality (A1FI and A2). The use of the SRES scenarios highlights several non-linearity's in the world food supply system, both in the biophysical sense, where the levels of atmospheric $\mathrm{CO} 2$ tested reach new levels, and the socio-economic sense, where changes in population dynamics and economic and political structures complicate the translation of biophysical climate change impacts into social indices, such as the number of people at risk of hunger.

Four major points emerge from the changes in crop yield study. First, in most cases the SRES scenarios exerted a slight to moderate (0 to $5 \%$ ) negative impact on simulated world crop yields, even with beneficial direct effects of $\mathrm{CO} 2$ and farm-level adaptations taken into account. The only scenarios that increase global crop yields are derived from the SRES A2 ensemble assuming full realization of the $\mathrm{CO} 2$ effects. The yield projections under the SRES A1FI scenario are the most negative. The results depend strongly on the full realization in the field of beneficial direct physiological $\mathrm{CO} 2$ effects on crop growth and water use as currently measured in experimental settings. The realization of these potential beneficial effects of $\mathrm{CO} 2$ in the field remain uncertain due primarily to potential, yet still undocumented, interactions with nutrients, water, weeds, pests, and other stresses. If the climate change effects dominate, world crop yields are likely to be more negatively affected, as all scenarios project negative results (_9\% to _22\%), especially the A1 and A2 scenarios (_16\% to _22\%). Second, at the greater amounts of climate change tested in the A1 and A2 SRES scenarios, climate change is likely to increase the disparities in cereal yields between developed and developing countries in a more significant way than has been found in previous studies. Third, the SRES scenarios of a more globalised world (A1FI and B1) experience greater reduction in yield than the scenarios of a more regionalized world (A2 and B2) Fourth and finally, the use of ensemble realizations of the SRES scenarios highlights the regional uncertainties inherent even under similar greenhouse gas emissions pathways. Members of the A2 and B2 ensemble climate scenarios produce moderate differences in the crop yield results in some regions and time slices. These results point to the need for agricultural managers to prepare for a range of agricultural futures at the regional level. When the crop yield results are introduced to the BLS world food trade system model, the combined model and scenario experiments demonstrate that the world, for the most part, appears to be able to continue to feed itself under the SRES scenarios during the rest of this century.

The explanation for this is that production in the developed countries generally benefits from climate change, compensating for declines projected for developing nations. While global production appears stable, regional differences in crop production are likely to grow stronger through time, leading to a significant polarization of effects, with substantial increases in risk of hunger amongst the poorer nations, especially under scenarios of greater inequality (A1FI and A2). The results illustrate the complex nature of the food supply system where moderate increases in air temperatures do not necessarily mean shortfalls in cereals. More so than ever before, the use of the new SRES emissions and climate scenarios has highlighted the non-linearity in the food supply system. It has also highlighted the sensitivity of the results to the balance between $\mathrm{CO} 2$ fertilization and changes in climate, hence the presentation in this paper of yield change potentials with and without $\mathrm{CO} 2$ enhancement. It should also be noted that the impact range produced by the spatial and temporal variations evident between individual HadCM3 ensemble members is also significant. By the 2080s, the variation around the global average directly attributable to natural variability is more than $50 \%$ of the mean climate change signal. This uncertainty will need to be borne in mind by policymakers. These results suggest we should be looking not just to avoid a warmer world but also looking for 
ways to adapt to a more uncertain world where in certain regions the risk of crop failure on a year-to-year basis is likely to increase.

\section{Abdulla DIKU (2011) [7]}

Conducted a study on agriculture is the most climate sensitive of all economic sectors. In Albania, the impacts of climate change on the agricultural sector represent an urgent problem, since the majority of the rural population depends either directly or indirectly on agriculture. The rural poor will be disproportionately affected because of their greater dependence on agriculture, their relatively lower ability to adapt, and the high proportion of their income that is spent on food.

The impacts of climate change could therefore undermine the progress that has been made in poverty reduction and could adversely affect food security and economic growth in vulnerable rural areas. Increased exposure to high temperatures, drought, and shifting seasonal patterns, increased incidence of diseases and pests and soil erosion are already beginning to damage agricultural productivity. At the same time, climate vulnerability has been exacerbated by sub-optimal policies, the deficient management of natural resources and associated infrastructure, and poor adaptive capacities. Soil erosion is a huge problem: 60 percent of the territory is affected, while 30 percent of agricultural land has annual soil loss rates of around 20 to 70 tons/ha. As the agricultural sector is the biggest consumer of fresh water, at 60 percent of the total, water resources are an important issue. Extreme events such as floods, droughts and fires have occurred in recent years, but no integrated assessment has been carried out to measure the costs from an economic, social and environmental perspective. Climate change influences a range of biophysical factors, including plants and animals, water, biodiversity and nutrient cycles, as well as the ways in which these are managed through agricultural practices and land use for food production. However, there is still little available capacity within the

Ministry of Agriculture, Food and Consumer Protection and its agencies at regional and local levels to provide information and assist farmers in coping with climate change effects, risks and opportunities.

It is essential to mainstream and integrate climate change issues into policy and investment decisions, since changes in agricultural patterns and performance will affect food supply at local as well as global levels. In low-income countries that have limited financial capacity to trade and that are highly dependent on their own production to meet demand, it may not be possible to offset reductions in local supply without increasing reliance on food aid. At the same time, producer groups that are less able to deal with climate change, such as the rural poor in developing countries, risk having their safety and welfare compromised.

The article concludes that there is a significant difference in weather conditions in Vojvodina during the 1995 to 2005 period compared to the 1985 to 2005 reference period. Precipitation records indicate positive and negative trends, while a strong temperature gradient in the SE-NW direction can be observed. In addition, during the 1995 to 2005 period, warmer winters and an increased frequency of spring frost are accompanied by warm periods during the spring and an increased numb er of extreme weather events. It should be noted that the number of extremely hot days increased in the first half of the year and decreased in the second half. This led to increased variation being the most pronounced characteristic of the climate in Vojvodina during the last decades of the 20th century, particularly with respect to precipitation. An increased number of extreme weather events and variations in precipitation are common features of the current state of climate change in Vojvodina. From the agricultural point of view, the greatest naturally caused agricultural losses in Vojvodina are related to extreme weather events (drought, spring frost, hail, floods). Changed climate conditions also contributed to the change in the structure of pests and plant diseases that was registered in recent years.

According to results based on the dynamic downscaling of the SX-G climate model, temperatures in Serbia will increase by $1 \mathrm{oC}$ in the 2001 to 2030 period; and by more than $3 \mathrm{oC}$ in the 2071 to 2100 period. In the first 30 years 
of the $21 \mathrm{st}$ century, the expected change in the amount of precipitation in Serbia is positive (20 to $30 \mathrm{~mm} / \mathrm{year}$ ), while for the last 30 years the country as a whole will be much drier (with a decrease in precipitation of up to 30 $\mathrm{mm} /$ year), with the exception of Vojvodina.

According to the statistically downscaled outputs of HadCM3, ECHAM5 and NCAR-PCM, annual temperatures in Vojvodina are expected to rise by $1.3 \mathrm{oC}$ by 2040 ; and by $2.4 \mathrm{oC}$ by 2080 . There are no significant differences among climate models in the projected relative change in annual temperature. Accumulated temperatures above $0 \mathrm{oC}$ during the winter wheat vegetation period in Vojvodina (October to June) are expected to be 8.6 to 12 percent higher in 2040 and 17.8 to 25.67 percent higher in 2080 . The mean air temperature during the winter wheat vegetation period is expected to be 10.5 to 15.5 percent higher in 2040; and 21.7 to 28.0 percent higher in 2080, depending on the climate model and location.

Spring crops will be more affected by the increased number of crop drying days and the projected higher temperatures during the late spring and summer. According to the results obtained, during the spring crops growing season a temperature increase from 4.9 to 8.9 percent is projected for 2040 and from 10.8 to 16.6 percent for 2080 .

Following the SIRIUS crop model, which was run with statistically downscaled GCM outputs, it seems that the winter wheat yield will generally decrease in the absence of a significant increase in $\mathrm{CO} 2$ concentration. However, anticipating climate change effects without a change in $\mathrm{CO} 2$ concentration is not very reasonable. Hence, taking into account $\mathrm{CO} 2$ impacts, a significant increase in winter wheat yield can be expected in the range of 28 to 73.6 percent. Regarding adaptation strategy, it is important to take into account the numerous economic, legal and institutional limitations that affect the application of appropriate adaptation measures. The most important economic problems are related to the high costs of introduction, unfavorable bank credits and the undeveloped market. Additionally, farmers have no influence on the prices of inputs and outputs; and subventions for plant production are very limited and highly dependent on the trade sector. It should be noted that the privatization of the food industry is still not complete, which is a source of additional problems. For these reasons, and in this phase of realization, the planned adaptation measures should be focused on reducing evapotranspiration; crop rotation; decreasing spring crops and increasing winter crops in order to make better use of soil water; reducing soil cultivation and improving soil structure; changing sowing dates; and changing crops and cultivars to less demanding varieties. In terms of vine quality and production, the direction of changes should be towards more adaptable varieties and vineyard regionalization, in which production areas will be shifted to regions at higher altitudes that have a more appropriate climate for existing varieties. By way of conclusion, it can be stated that there are a huge number of steps that could improve agricultural adaptation to climate change, which can be taken in spite of the current economic problems in Serbia.

\section{CONCLUSIONS}

The following conclusions were drawn by reviewing the articles on impact of climate change on food security.

- The importance and the overall impact of climate change on food production will differ across regions and over time.

- Food security can be achieved by paying higher attentions to issues such as climate change, integrated management, agricultural pricing and crop insurance.

- A simulation model can be developed to determine the optimal cultivated area, cropping pattern and irrigation efficiency considering limited water supply resources in a region to study the potential regional-scale impacts of climate change on the crop water requirements.

- The impossibility of projecting irrigated areas under changed climatic conditions and the projected future percent of cultivated area irrigated is proposed as the geographical indicator of climate change effects on irrigation.

- The risk of agricultural crops water demand and the evaluation of monthly temperature under climate change scenarios in future periods can be simulated using a model.

\section{ACKNOWLEDGEMENTS}


I am thankful Professor and Head, Dept of Civil Engineering, Principal of ACS College of Engineering and BMS College of Engineering, my beloved friends Umadevi R, Sugandha N, Kavitha S for their timely help rendered and the immense support extended for the submission of this paper.

\section{REFERENCES}

[1] P. S. Brahmanand, A. Kumar, S. Ghosh, S. Roy Chowdhury, R. B. Singandhupe, R. Singh, P. Nanda, H. Chakraborthy, S. K. Srivastava and M. S. Behera," Challenges to food security in India" CURRENT SCIENCE, VOL. 104, NO. 7, 10 APRIL 2013.

[2] Josef Schmidhuber and Francesco N. Tubiello, "Global food security under climate change", PNAS, vol. 104, No. 50, December 11, 2007.

[3] Mohammad Karamouz, F, Behzad Ahmadi and Zahra Zahmatkesh, "Developing an Agricultural Planning Model in a Watershed Considering Climate Change Impacts", ASCE, 139(4): 349-363, 2013.

[4] By Dean F, Peterson and Andrew A. Keller, "Effects Of Climate Change On U.S. Irrigation", ASCE, 116(2): 194-210, 1990.

[5] Parisa-Sadat Ashofteh, Omid Bozorg Haddad and Miguel A. Marino, "Risk Analysis of Water Demand for Agricultural Crops under Climate Change", ASCE, 0(4): 04014060, 2015.

[6] M.L. Parry, C. Rosenzweig, A. Iglesias, M. Livermore, G. Fischer, "Effects of climate change on global food production under SRES emissions and socio-economic scenarios", Global Environmental Change,Elsevier, 14, 2004

[7] Abdulla DIKU, "The impact of climate change on food production/selected crop yields in Albania", "Impacts of Climate Change on Food Production in the Western Balkan Region”, July 2011. 